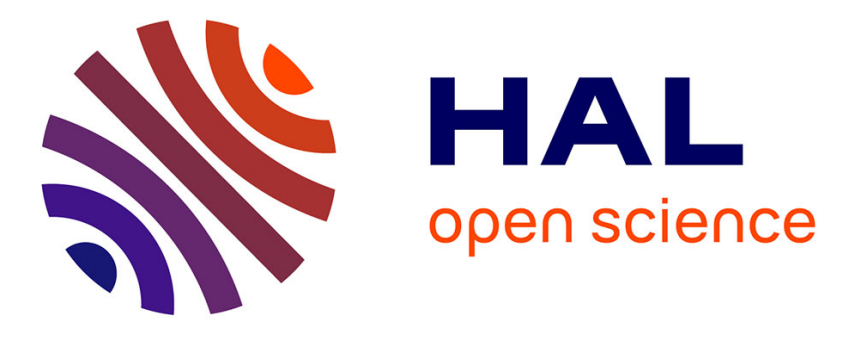

\title{
Water-based acrylic coatings reinforced by PISA-derived fibers
}

\author{
Richard Albigès, Pauline Klein, Stéphanie Roi, François Stoffelbach, \\ Costantino Creton, Laurent Bouteiller, Jutta Rieger
}

\section{> To cite this version:}

Richard Albigès, Pauline Klein, Stéphanie Roi, François Stoffelbach, Costantino Creton, et al.. Waterbased acrylic coatings reinforced by PISA-derived fibers. Polymer Chemistry, 2017, 8 (34), pp.49924995. 10.1039/C7PY00302A . hal-01618807

\section{HAL Id: hal-01618807 https: / hal.sorbonne-universite.fr/hal-01618807}

Submitted on 18 Oct 2017

HAL is a multi-disciplinary open access archive for the deposit and dissemination of scientific research documents, whether they are published or not. The documents may come from teaching and research institutions in France or abroad, or from public or private research centers.
L'archive ouverte pluridisciplinaire HAL, est destinée au dépôt et à la diffusion de documents scientifiques de niveau recherche, publiés ou non, émanant des établissements d'enseignement et de recherche français ou étrangers, des laboratoires publics ou privés. 


\title{
Water-based acrylic coatings reinforced by PISA-derived fibres
}

\author{
Richard Albigès ${ }^{a}$, Pauline Klein ${ }^{a}$, Stéphanie Roi ${ }^{a}$, François Stoffelbach $^{a}$, Costantino Creton ${ }^{b, c, d}$, \\ Laurent Bouteiller $^{a}$ and Jutta Rieger ${ }^{a}{ }^{*}$ \\ Polymerization-induced self-assembly (PISA) is an efficient approach to synthesize self-assembled core-shell nanofibres in \\ water, made of amphiphilic block copolymers. We demonstrate here for the first time that such anisotropic and high Tg \\ nanofibres can be used as reinforcing fillers for water-based acrylic materials. This strategy opens the way for strong all- \\ organic aqueous coatings.
}

There is an increasing demand from the coating industry to reduce the amount of volatile organic compounds (VOC). ${ }^{1}$ For instance, solvent-based paints are replaced by water-based latex paints, obtained through radical emulsion polymerization processes. However, most of the formulations still contain VOCs used to assist the film formation at low temperature by plasticizing the polymer in the latex particles. Alternatively, the latex particles can be softened by changing the composition to lower the glass transition temperature $(\mathrm{Tg})$. This provides good deformability as the films dry, but the resulting materials exhibit generally poor mechanical properties. A solution to obtaining stiffer rubbery materials without sacrificing deformability is the introduction of hard fillers, such as inorganic silica particles or carbon black. However reported disadvantages are loss of transparency, increase in density and the relatively high amount of filler necessary. ${ }^{2,3}$ To reduce the amount of filler, the addition of anisotropic fillers such as glass fibres, carbon nanotubes ${ }^{4,5}$ or natural fibres ${ }^{6}$ has also been considered. Thanks to their high aspect ratio, percolation and thus an increase of the mechanical performance can be reached with very low amounts of these additives. However, these fillers are difficult to tune (in terms of composition and diameter) and to disperse. Alternatively, polymeric composite films have been proposed that are made of latex blends ${ }^{7}$, mainly mixtures of soft with hard spherical particles ${ }^{8,9}$, but also reactive blends ${ }^{10}$ or structured core-shell latexes, to form

\footnotetext{
Sorbonne Universités, UPMC Univ Paris 6, CNRS, Institut Parisien de Chimie Moléculaire, Polymer Chemistry Team, UMR 8232, 4 place Jussieu, 75005 Paris, France, jutta.rieger@upmc.fr

b. Sorbonne Universités, UPMC Univ Paris 6, CNRS, Laboratoire SIMM, 10, rue Vauquelin, 75005 Paris, France

CNRS, ESPCI Paris, PSL Research University, Laboratoire SIMM, 10 rue Vauquelin 75005 Paris, France

d. Global Station for Soft Matter, Global Institution for Collaborative Research and Education, Hokkaido University, Sapporo, Japan

Electronic Supplementary Information (ESI) available: Materials and methods section, scheme of the synthetic pathway, detailed Tables for the polymerization including polymerization conditions and polymer/latex characterization, size exclusion chromatograms of the polymers, additional TEM and stress-strain plots, creep test.
}

nanostructured films with suitable properties. ${ }^{11}$ In particular we reported recently how one can take advantage of the current developments in polymerization-induced self-assembly (PISA) to prepare nanostructured latex-based films combining high stiffness and high deformability, seemingly contradictory properties. $^{12,13}$ The materials were exclusively made of spherical soft-core/hard-shell particles, constituted of highly asymmetric poly(acrylic acid)- $b$-poly( $n$-butyl acrylate), PAA- $b$ PBA, block copolymers, synthesized in water thanks to a RAFT emulsion polymerization process. ${ }^{14}$ The enhanced stiffness of the materials at low strain was attributed to the percolating network formed by the glassy PAA shells. Unfortunately, these formerly reported materials are entirely made of relatively costly PISA-derived particles which may be seen as a limitation of the approach.

In this work, we propose a new concept to design reinforced all-organic water-based soft coatings taking advantage of the most recent developments in PISA and existing latex blend strategies. It has been shown that the morphology of the amphiphilic copolymer self-assemblies can be reproducibly tuned from a spherical shape to anisotropic filamentary structures (also called worm-like) by subtle changes in the polymerization conditions, and that aqueous fibre dispersions can be obtained in high concentration and yields. ${ }^{15,16}$ We propose here to use high $\mathrm{Tg}$ nanofibres, in the form of selfstabilized aqueous dispersions, obtained by PISA, as reinforcing additives for water-based soft acrylic films. In this pioneering work, the materials are obtained from simple mixtures of a conventional low $\mathrm{Tg}$ latex with limited quantities of PISA-derived polystyrene (PS) nanofibres. The mechanical properties of this new class of films made from latex blends were evaluated by tensile tests. Materials reinforced with the spherical counterparts were used as reference. The increased stiffness of the fibre-reinforced materials (while maintaining high extensibility) was explained by the high aspect ratio of the fillers which may form a reinforcing network of glassy nanofibres. 
Table 1. Synthesis of aqueous fibre and sphere dispersions by PISA in two successive polymerization steps. ¥

1st step: Synthesis of macroRAFT agents in aqueous solution

\begin{tabular}{|c|c|c|c|c|c|c|c|}
\hline entry & $\begin{array}{l}{[\mathrm{MAA}]_{0}} \\
/ \mathrm{mol} \mathrm{L}^{-1}\end{array}$ & $\begin{array}{l}{[\text { PEOMA }]_{0}} \\
/ \mathrm{mol} \mathrm{L}^{-1}\end{array}$ & $\begin{array}{l}{[\mathrm{CTPPA}]_{0}} \\
/ \mathrm{mol} \mathrm{L}^{-1}\end{array}$ & $\begin{array}{l}\text { Conv. } \\
/ \%\end{array}$ & $\begin{array}{l}M_{\mathrm{n}, \mathrm{th}} \\
/ \mathrm{kg} \\
\mathrm{mol}^{-1}\end{array}$ & $\begin{array}{l}M_{\mathrm{n}, \mathrm{Ls}} \\
/ \mathrm{kg} \\
\mathrm{mol}^{-1}\end{array}$ & $\theta^{\mathrm{PS}}$ \\
\hline M-S1 & 0.20 & 0.20 & 0.013 & 97 & 16 & 25 & 1.12 \\
\hline M-F1 & 0.25 & 0.12 & 0.009 & 99 & 15 & 22 & 1.12 \\
\hline M-F2 & 0.40 & 0.20 & 0.014 & 97 & 16 & 25 & 1.11 \\
\hline
\end{tabular}

2nd step: Synthesis of aqueous fibre dispersions and spherical latexes via aqueous emulsion polymerization.

\begin{tabular}{lllllll}
\hline entry & Morphology & $\begin{array}{l}{[\mathrm{S}]_{0}} \\
/ \mathbf{~ m L}{ }^{-1}\end{array}$ & $\begin{array}{l}{[\mathrm{S}]_{0} /[\text { macro- }} \\
\text { RAFT }]_{0}\end{array}$ & $\begin{array}{l}\boldsymbol{M}_{\mathrm{n}, \text { th }} \\
/ \mathrm{kg} \mathrm{mol}^{-1}\end{array}$ & $\begin{array}{l}\boldsymbol{M}_{\mathrm{n}, \mathrm{LS}} \\
/ \mathrm{kg} \mathrm{mol}^{-1}\end{array}$ & $\boldsymbol{\theta}^{\text {PS }}$ \\
\hline S1 & spheres & 0.21 & 300 & 47 & 58 & 1.32 \\
F1 & fibres & 0.13 & 300 & 46 & 53 & 1.15 \\
F2 & fibres & 0.21 & 300 & 47 & 63 & 1.29 \\
\hline
\end{tabular}

The core-shell fibre dispersions based on a hard polystyrene core and a stabilizing poly(methacrylic acid)-copoly(methoxy(polyethylene oxide) methacrylate) P(MAA-coPEOMA) $\left(M_{\mathrm{n}}\right.$ of PEOMA $\left.=950 \mathrm{~g} \mathrm{~mol}^{-1}\right)$ shell were prepared entirely in water, in two successive polymerization steps (Table 1). In a first step MAA and PEOMA (MAA/PEOMA = 67/33) were copolymerized in water in the presence of 4-cyano-4thiothiopropylsulfanylpentanoic acid (CTPPA) as a chain transfer agent, using 4,4-azobis(4-cyanopentanoic acid) (ACPA) as a radical initiator (see Scheme $\mathrm{SI}-1$ ). ${ }^{17,18}$ The polymerization reached full conversion within $2 \mathrm{~h}$ yielding the water-soluble statistical macroRAFT agent P(MAA-Co-PEOMA) $\left(\theta=1.1, M_{n, L S}\right.$ $=22 \mathrm{~kg} \cdot \mathrm{mol}^{-1}$ ) constituting in fine the stabilizing shell of the latex particles. The reaction medium was adjusted to $\mathrm{pH} 5$ in order to ensure particle stabilization by the partially deprotonated carboxylic acid groups of MAA, and then styrene and a supplementary amount of initiator in water were added, and the polymerization was pursued in the same flask in emulsion conditions and under inert atmosphere. This second polymerization step was stopped after $3.5 \mathrm{~h}$ and the aqueous fibre dispersion was recovered as a viscous liquid. Size exclusion chromatography (Figure SI-1) assessed the good control over the polymerization and the successful formation of P(MAA-co-PEOMA)- $b$-PS diblock copolymers with low molar mass dispersity $\left(\Theta<1.2, M_{\mathrm{n}, \mathrm{LS}}=53 \mathrm{~kg} \cdot \mathrm{mol}^{-1}\right.$, Table 1 , fibres F1). TEM showed the formation of micrometres long nanofibres, with an average diameter about $50 \mathrm{~nm}$ (Figure 1A).

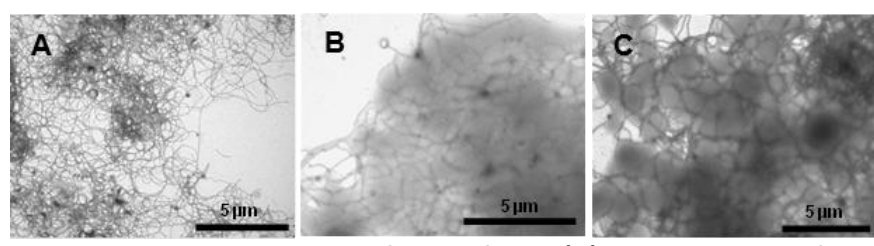

Figure 1. TEM micrographs of dried fibres (A), and mixtures of th soft acrylic latex with 5 wt\% (B) and $10 w t \%(C)$ of fibres (pH = 12).

For comparison spherical core-shell particles based on the same type of polymer were also prepared by PISA according to the same protocol, using a different MAA/PEOMA molar ratio
$(50 / 50)$ in order to promote the formation of spheres instead of fibres. ${ }^{18}$ Again, SEC confirmed the formation of amphiphilic diblock copolymers with good control $\left(E=1.3, M_{\mathrm{n}, \mathrm{LS}}=58\right.$ kg. $\mathrm{mol}^{-1}$ ). Like in the fibre synthesis, a small amount of residual macroRAFT agent was detected, that is to say both samples contain some free P(MAA-Co-PEOMA) chains. Moreover, the average molar mass of each block was comparable for both systems (Table 1 and Table SI-1). However, TEM assessed that spheres instead of fibres (with similar diameter, $45 \mathrm{~nm}$, Figure $\mathrm{SI}-2$ ) were obtained, simply by changing the molar ratio of the hydrophilic comonomers. As illustrated in Scheme SI-2, acrylic films were then prepared from a typical soft acrylic latex (statistical copolymer P(nBA-co-AA), $1.9 \mathrm{wt} \% \mathrm{AA}$, see $\mathrm{SI}$ ) used for pressure-sensitive-adhesives ${ }^{19}$ to which 5 wt\% of glassy fibre (F1) or sphere (S1) latex were added as a reinforcing filler. A reference film without filler was also formed in the same drying conditions (see Series I, Film-pH5.5, Film5\%F-pH5.5 and Film5\%S-pH5.5 in Table 2). Standard tensile tests were then performed to evaluate the impact of the incorporation of the glassy filler in the soft acrylic polymer matrix. For strains below $10 \%$ the films presented a linear behaviour, but for larger strains all films underwent a progressive softening, before break-up only beyond $1000 \%$ extension (see Figure 2 and Figure SI-3), as typically observed for soft PBA films. As summarized in Table 2, the addition of $5 \mathrm{wt} \%$ fibres increased the Young's modulus by a factor of 2, whereas the corresponding spherical particles showed only a slight increase of modulus. This first series (I) was prepared from mixtures of the acrylic matrix latex without $\mathrm{pH}$ adjustment, i.e. at pH 5.5.
A

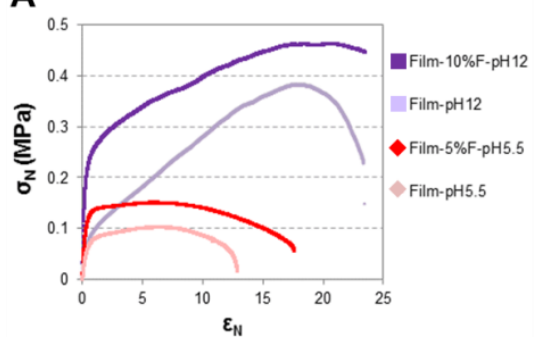

B

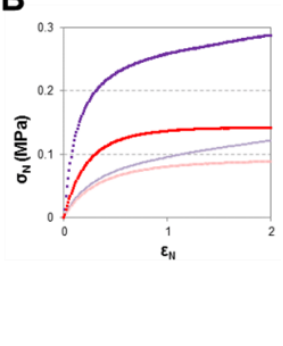

Figure 2. (A) Nominal stress $(\sigma)$-strain $(\varepsilon)$ curve for pristine films and films containing fibres at $\mathrm{pH}=5.5$ or 12 (strain rate $=0.1 \mathrm{~s}^{-1}$ ), (B) Enlargement of the low strain region.

For the next series of films, the latex blends were prepared in alkaline conditions in order to more efficiently deprotonate the carboxylic acid groups of the MAA units which should decrease inter-fibre interaction via $\mathrm{H}$-bonding (by MAA dimerization or interaction of MAA with PEO) and thus promote a better dispersion of the fibres in the acrylic latex. Various amounts of spherical or fibre additive (5 or $10 \mathrm{wt} \%$ ) were tested (Figure SI-4) and a reference film was also cast at the same $\mathrm{pH}$. The comparison of the reference films formed at $\mathrm{pH} 5.5$ or 12, in Figure 2, shows that the film made at $\mathrm{pH} 12$ was much stiffer, in the medium strain region, and more extensible, while maintaining a similar Young's modulus as the film formed at $\mathrm{pH}$ 5.5. The observed stiffening through $\mathrm{pH}$ increase is a known phenomenon in acrylic acid (AA) containing formulations ${ }^{7,20}$ and it is usually explained by the formation of long lived ionic clusters. It must therefore be 
taken into account in the interpretation of the films incorporating the glassy additives.

Table 2. Film composition and results of the tensile tests.

\begin{tabular}{|c|c|c|c|c|c|c|c|}
\hline$\#$ & Film & $\begin{array}{l}\text { Addi } \\
\text { tive }\end{array}$ & $\begin{array}{l}\text { wt\% } \\
\text { additive }\end{array}$ & $\begin{array}{l}\sigma_{\max }^{\mathrm{b}} \\
/ \mathrm{MPa}\end{array}$ & $\varepsilon_{B}^{b}$ & $\begin{array}{l}\mathrm{E}^{\mathrm{c}} \\
/ \mathrm{MPa}\end{array}$ & $E / E_{0}{ }^{c}$ \\
\hline \multicolumn{8}{|c|}{ Series I prepared from $P(n B A-c o-A A)$ latex 1 at $p H 5.5^{a}$} \\
\hline 1 & $\begin{array}{l}\text { Film- } \\
\text { pH5.5 }\end{array}$ & - & - & $\begin{array}{l}0.10 \\
\pm 0.01^{\mathrm{e}}\end{array}$ & $\begin{array}{l}12 \\
\pm 1^{\mathrm{e}}\end{array}$ & $\begin{array}{l}0.29 \\
\pm 0.03^{e}\end{array}$ & 1.0 \\
\hline 2 & $\begin{array}{l}\text { Film5\%S- } \\
\text { pH5.5 }\end{array}$ & S1 & 5 & $\begin{array}{l}0.13 \\
\pm 0.01\end{array}$ & $\begin{array}{l}10 \\
\pm 1\end{array}$ & $\begin{array}{l}0.37 \\
\pm 0.03\end{array}$ & 1.3 \\
\hline 3 & $\begin{array}{l}\text { Film5\%F- } \\
\text { pH5.5 }\end{array}$ & $\mathrm{F} 1$ & 5 & $\begin{array}{l}0.15 \\
\pm 0.01 \\
\end{array}$ & $\begin{array}{l}16 \\
\pm 2\end{array}$ & $\begin{array}{l}0.59 \\
\pm 0.04\end{array}$ & 2.0 \\
\hline \multicolumn{8}{|c|}{ Series II prepared from $P(n B A-c o-A A)$ latex 1 at $p H 12^{a}$} \\
\hline 4 & $\begin{array}{l}\text { Film- } \\
\text { pH12 }\end{array}$ & - & - & $\begin{array}{l}0.41 \\
\pm 0.08\end{array}$ & $\begin{array}{l}26 \\
\pm 3\end{array}$ & $\begin{array}{l}0.33 \\
\pm 0.05\end{array}$ & 1.0 \\
\hline 5 & $\begin{array}{l}\text { Film5\%S- } \\
\text { pH12 }\end{array}$ & S1 & 5 & $\begin{array}{l}0.25 \\
\pm 0.02\end{array}$ & $>25^{d}$ & $\begin{array}{l}0.51 \\
\pm 0.03\end{array}$ & 1.5 \\
\hline 6 & $\begin{array}{l}\text { Film10\%S } \\
\text {-pH12 }\end{array}$ & S1 & 10 & $\begin{array}{l}0.27 \\
\pm 0.02\end{array}$ & $>25^{d}$ & $\begin{array}{l}0.79 \\
\pm 0.05\end{array}$ & 2.4 \\
\hline 7 & $\begin{array}{l}\text { Film5\%F- } \\
\text { pH12 }\end{array}$ & $\mathrm{F} 1$ & 5 & $\begin{array}{l}0.34 \\
\pm 0.02\end{array}$ & $>29^{d}$ & $\begin{array}{l}0.89 \\
\pm 0.07\end{array}$ & 2.7 \\
\hline 8 & $\begin{array}{l}\text { Film10\%F } \\
\text {-pH12 }\end{array}$ & F1 & 10 & $\begin{array}{l}0.44 \\
\pm 0.04\end{array}$ & $>25^{d}$ & $\begin{array}{l}1.54 \\
\pm 0.09\end{array}$ & 4.7 \\
\hline
\end{tabular}

${ }^{\mathrm{a}} \mathrm{pH}$ of the latex or the latex mixture before film formation, ${ }^{b} \sigma_{\max }=$ maximum stress, $\varepsilon_{B}=$ strain at break $=\left(L_{B}-L_{0}\right) / L_{0},{ }^{c} E=$ Young's modulus, $E_{0}=$ Young's modulus of the reference film prepared at the same $\mathrm{pH}$ without additive, ${ }^{\mathrm{d}}$ in the experimental set-up the film was extended without failure, ${ }^{\mathrm{e}}$ standard deviations on at least 3 samples.

As summarized in Table 2, upon addition of either 5 or 10 wt\% of additive, all films of series II remained highly extensible (extension $\geq 2500 \%)^{\S}$ indicating that the glassy additives were a priori well-dispersed in the soft acrylic matrix. The successful dispersion of the fibres was confirmed by TEM images of thin films made from the corresponding mixtures (Figure $1 \mathrm{~B}$ and $\mathrm{C}$ ). Clearly, the desired stiffening of the materials was observed in the low strain region (Figure $2 \mathrm{~B}$ ). As for series I, the addition of the glassy fibres $\mathbf{F 1}$ led to a clear increase in stiffness revealed by an increase of the Young's modulus by a factor of 2.7 (with 5 wt\% F1) or 4.7 (with 10 wt\% F1), respectively (Table 2, E/ $E_{0}$ ). Again, the values obtained for the fibre-containing films outperformed by far the effect of the corresponding spherical filler, which enhanced the Young's modulus by a factor of 2.4 at most (using 10 wt\% of S1). The effect of the filler morphology on the modulus at the different $\mathrm{pH}$ is summarized in Figure 3. The strong influence of the filler morphology means that the possible presence of carboxylate clusters is not the main reason for the observed results." The results may rather be explained by the high aspect ratio of the fibre latex F1, which suggests the formation of a quasi-percolating network of glassy PS fibres, which would be in turn responsible for the observed amplification of the modulus increase.

In order to test the robustness and versatility of the approach, we prepared a third series of films in alkaline conditions using a home-made soft acrylic latex (matrix latex 2 in the SI). Compared to the first soft latex, this latex possessed a slightly higher AA content (2.9 wt\%, compared to $1.9 \mathrm{wt} \%$ in latex 1 ), and a gel fraction of $55 \%$. The resulting blanc film was thus much less extensible $\left(\varepsilon_{\mathrm{B}}<7\right)$ than the blanc films prepared with latex 1 . The results of the mechanical tests are summarized in Table SI-2 in the Supporting Information. Again, the use of fibres instead of spheres increased the Young's modulus by a factor of 2.3 and 5.2 (instead of 1.4 and 2.8, for 5 and $10 \mathrm{wt} \%$ additive respectively). This amplification of the reinforcement suggests again the formation of a network by the fibres and demonstrates the robustness of the approach.

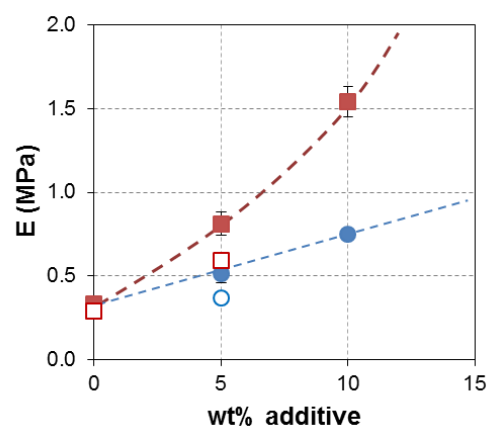

Figure 3. Evolution of the films' Young's modulus with increasing amount of additive, at pH 12 ( $\square$ = fibres, $\bullet=$ spheres) and pH 5.5 ( $\square$ = fibres, $\mathrm{O}$ = spheres).

Finally, to further illustrate the potential of this new class of latex blend materials, a creep resistance experiment was performed (using a constant load of $10 \mathrm{~g}$ ) with sample Film5\%F-pH5.5 containing only 5 wt\% of fibres and compared to the reference sample (Film-pH5.5) without additive and prepared at the same $\mathrm{pH}(\mathrm{pH}=5.5)$. As demonstrated in Figure SI-5, the film containing the fibres was hardly extended and broke only after $5 \mathrm{~h} 30 \mathrm{~min}$ whereas the reference film failed after $1 \mathrm{~h}$ in the same conditions.

\section{Conclusions}

PISA is nowadays recognized as an efficient and valuable approach to synthesize nanofibres made of amphiphilic block copolymers, in high solids contents, in water. In this communication, we demonstrated for the first time the potential of as-prepared high $\mathrm{Tg}$ nanofibres as reinforcing fillers for soft acrylic water-based coatings. The composite materials were prepared from simple mixtures of a soft standard acrylic latex to which high Tg fibres were simply added as an aqueous dispersion. Comparison with a reference material reinforced with the spherical counterparts suggests that the high aspect ratio of the fibre-type fillers allows the formation of a reinforcing network of glassy nanofibres, which is responsible for the observed increased stiffness of the materials, while maintaining a high extensibility. This new approach is expected to pave the way to a new class of waterbased coatings, that are environmental friendly (synthesis is exclusively water-based, no VOC additives) and simple to prepare (simple mixing process). In a future systematic study we will investigate the influence of the fibre length and diameter, as well as the nature of the core and shell polymer, in order to reduce the amount of additive.

\section{Acknowledgements}

We thank P. Beaunier (UPMC, LRS) for TEM analyses and fruitful discussions and R. Even from Dow Chemical for providing the matrix latex 1 . 


\section{Notes and references}

‡ For further details see Table SI-1

$\S$ If there is failure, it occurs at the clamp.

\# In addition, Figure 3 shows that the relative increase of the modulus from spherical filler to filamentary filler is similar at $\mathrm{pH}$ 12 and at $\mathrm{pH} \mathrm{5.5,} \mathrm{although} \mathrm{the} \mathrm{proportion} \mathrm{of} \mathrm{carboxylate} \mathrm{groups}$ is much lower at the lower $\mathrm{pH}^{2}$

${ }^{1}$ M. A. Winnik, J. Feng, J. Coat. Technol. 1996, 68, 39.

${ }^{2}$ L. Bokobza, Macromol. Mat. Eng. 2004, 289, 607.

${ }^{3}$ F. Khelifa et al. In Handbook of Smart Coatings for Materials Protection, Ed. A.S.H. Makhlouf, Woodhead Publishing Series, 2014, p. 423-458.

${ }^{4}$ T. Wang, C.-H. Lei, A.B. Dalton, C. Creton, Y. Lin, K. A. S. Fernando, Y.-P. Sun, M. Manea, J. M. Asua, J. L. Keddie, Adv. Mater. 2006, 18, 2730.

${ }^{5}$ T. Chatterjee et al. Soft Matter 2013, 9, 9515

${ }^{6}$ U. Gayer et al. Gummi, Fasern, Kunststoffe 2004, 57, 367.

${ }^{7}$ R. S. Gurney, A. Morse, E. Siband, D. Dupin, S. P. Armes, J. L. Keddie, J Colloid Interface Sci 2015, 448, 8.

${ }^{8}$ Y. Chevalier, M. Hidalgo, J.-Y. Cavaillé, B. Cabane, Macromolecules 1999, 32, 7887.

${ }^{9}$ K. B. Singh, G. Deoghare, M. S. Tirumkudulu, Langmuir, 2009, 25, 751.

${ }^{10}$ M. A. Winnik, J. Coat. Technol. 2002, 74 (925), 49.

${ }^{11}$ F. D. Dos Santos, P. Fabre, X. Drujon, G. Meunier, L. Leibler, J. Polym. Sci. Polym. Phys. 2000, 38, 2989.

${ }^{12}$ M. Chenal, J. Rieger, C. Vechambre, J.M. Chenal, L. Chazeau, C. Creton, L. Bouteiller, Macromol. Rapid Commun. 2013, 34, 1524.

${ }^{13}$ M. Chenal, C. Vechambre, J. M. Chenal, L. Chazeau, V. Humblot, L. Bouteiller, C. Creton, J. Rieger, Polymer, 2017, 109, 187.

${ }^{14}$ M. Chenal, L. Bouteiller, J. Rieger, Polym. Chem. 2013, 4, 752.

${ }^{15}$ J. Rieger, Macromol. Rapid Commun. 2015, 36, 1458.

${ }^{16}$ S. L. Canning, G. N. Smith, S. P. Armes, Macromolecules 2016, 49, 1985.

${ }^{17}$ X. Zhang, S. Boissé, W. Zhang, P. Beaunier, F. D'Agosto, J. Rieger, B. Charleux, Macromolecules 2011, 44, 4149.

18 W. Zhang, F. D'Agosto, O. Boyron, J. Rieger, B. Charleux, Macromolecules 2012, 45, 4075.

${ }^{19}$ F. Tanguy, M. Nicoli, A. Lindner, C. Creton Eur. Phys. J. E, 2014, 37, 1.

${ }^{20}$ T. Wang, E. Canetta, T. G. Weerakkody, J. L. Keddie, ACS Appl. Mater. Interfaces, 2009, 1, 631; J. Garrett, P. A. Lovell, A. J. Shea, R. D. Viney, Macromol. Symp., 2000, 151, 487.

${ }^{21}$ Y. Zhang, K. Han, D. Lu, Z. Liu, Soft Matter 2013, 9, 8723 